\title{
Erratum to: Water Quality Trends in the Loxahatchee National Wildlife Refuge
}

\author{
James A. Entry
}

Published online: 8 February 2013

(C) Springer Science+Business Media Dordrecht 2013

\section{Erratum to: Water Air Soil Pollut DOI 10.1007/s11270-012-1214-5}

The oginal publication of this article (DOI 10.1007/ s11270-012-1214-5) unfortunately contained errors.

The last sentence on page 4518, second column in 2.4 Statistical Analysis, The sentence reads "Trend analyses for the entire year were based on the center dry season months (June 1 through September 30) and wet season months (December 1 through March 31) because transition months may distort trend analysis (Helsel and Hirsch 2002)."

The wet and dry seasons are reversed. The sentence should read "Trend analyses for the entire year were based on the center wet season months (June 1 through September 30) and dry season months (December 1 through March 31) because transition months may distort trend analysis (Helsel and Hirsch 2002)."

The online version of the original article can be found at http://dx.doi.org/10.1007/s11270-012-1214-5

J. A. Entry $(\bowtie)$

Everglades Restoration Team, 950 N Krome Avenue,

Homestead, FL 33030, USA

e-mail: jim.entry@nutrigrown.com 